\title{
Novas Tendências dos Polímeros Epoxídicos. Propriedades Biológicas In Vitro de Formulações para Aplicações Médicas
}

\author{
Filiberto González Garcia, Maria E. Leyva, Alvaro A. A. de Queiroz \\ Departamento de Física e Química, Universidade Federal de Itajubá, MG
}

Olga Higa
Centro de Biotecnologia, Instituto de Pesquisas Energéticas e Nucleares, SP

\begin{abstract}
Resumo: Este trabalho descreve as propriedades biológicas in vitro de três formulações epoxídicas usando o monômero do tipo éter diglicidílico do bisphenol-A (DGEBA) com três co-monômeros do tipo poliamina alifática de maneira independente; trietilenotetramina (TETA), 1-(2-aminoetil)piperazina (AEP) e isoforonodiamina (IPD). As interações biológicas entre os polímeros obtidos e o sangue foram estudadas in vitro utilizando quatro métodos biológicos diferentes. Estudos de adsorção protéica, adesão plaquetária, formação de trombos e citotoxicidade são apresentados e discutidos. Os ensaios de adsorção protéica mostraram que a superfície dos polímeros adsorve mais albumina humana do que fibrinogênio humano. Os resultados de adesão plaquetária e formação de trombos indicaram que os sistemas DGEBA-IPD e DGEBA-AEP exibem boa hemocompatibilidade. Os três polímeros epoxídicos não revelaram toxicidade com células de ovário de hamster chinês. Os resultados obtidos indicam que os polímeros epoxídicos baseados no IPD obedecem aos critérios de hemocompatibilidade e citotoxicidade exigidos de um biomaterial. Os polímeros epoxídicos baseados nas aminas AEP e TETA exibem apenas um comportamento não citotóxico.
\end{abstract}

Palavras-chave: Éter diglicidílico do bisfenol-A, poliaminas alifáticas, adsorção protéica, adesão plaquetária, biocompatibilidade, citotoxicidade.

\section{New Trend for Epoxy Polymers. In Vitro Biological properties of Formulations for Medical Applications}

Abstract: In this paper the in vitro biological properties are presented for three epoxy networks based on diglycidyl ether of bisphenol-A epoxy prepolymer cured with aliphatic amines, namely triethylenetetramine (TETA), 1-(2-aminoethyl) piperazine (AEP) and isophoronediamine (IPD). The biological interactions between the fully-cured epoxy materials and blood were studied by in vitro methods. Research on the protein adsorption, platelet adhesion and thrombus formation is presented using a UV/VIS spectrometer and SEM analysis. Studies of protein adsorption onto polymeric surfaces showed that the three epoxy materials adsorbed more albumin than fibrinogen. Studies about platelet adhesion and thrombus formation of two epoxy polymers indicated that AEP and IPD network exhibits good hemocompatible behavior. The epoxy materials revealed no signs of cytotoxicity to Chinese hamster ovary cells, showing a satisfactory cytocompatibility. Therefore, the citotoxicity assays suggest that the three epoxy polymers are biocompatible materials.

Keywords: Diglycidyl ether of bisphenol-A, aliphatic amines, protein adsorption, platelet adhesion, biocompatibility, citotoxicity.

\section{Introdução}

Cirurgias de artroplastia total de quadril incluem o uso de próteses metálicas de ligas de titânio de alto desempenho e de cimentos para promover a adesão entre a prótese metálica e o tecido ósseo ${ }^{[1,2]}$. Além disto, a preparação de próteses para a reposição de um e/ou mais elementos na área odontológica precisa de materiais sintéticos biocompatíveis. Tanto os cimentos ósseos utilizados atualmente em ortopedia para promover a adesão entre o metal e o osso, assim como os materiais sintéticos mais utilizados na área odontológica são formulados à base de polímeros acrílicos, envolvendo monômeros vinílicos bifuncionais tais como; dimetacrilatos $^{[2-4]}$.

As resinas epoxídicas constituem uma das mais importantes classes de polímeros termorrígidos utilizados como matrizes em compósitos e recobrimentos. Estes materiais apresentam dureza, resistência química, baixa contração, assim como excelente adesão, como resultado da natureza estrutural dos monômeros que formaram a rede tridimen-

Autor para correspondência: Filiberto González Garcia, Laboratório de Biomateriais, Departamento de Física e Química, Instituto de Ciências Exatas, Universidade Federal de Itajubá (UNIFEI), Av. BPS 1303, Bairro Pinheirinho, CEP: 37500-903, Itajubá, MG, Brasil. E-mail: fili@unifei.edu.br 
sional. Estes materiais poliméricos apresentam grandes potencialidades para serem utilizados em algumas aplicações medicas se apresentarem biocompatibilidade, estabilidade dimensional e propriedades mecânicas adequadas.

Alguns polímeros formulados com resina do tipo éter diglicidílico do bisfenol-A (DGEBA) tem sido utilizados para preparar compósitos reforçados para aplicações em ortopedia e em odontologia ${ }^{[5,6]}$. Entretanto, numerosos estudos relacionados às propriedades de biocompatibilidade de diferentes monômeros epoxídicos e alguns poucos polímeros epoxídicos têm sido divulgados na literatura. Contudo, os trabalhos não envolvem estudos relacionados com polímeros epoxídicos formulados utilizando co-monômeros do tipo poliaminas alifáticas e sua interação com sangue.

Está bem estabelecido na literatura que o desempenho de uma prótese polimérica é prejudicado pela coagulação sanguínea, provocada pelo contato do sangue com a superfície do material implantado. O controle da coagulação sanguínea e de inflamações induzidas pela superfície do polímero pode ser controlado localmente ${ }^{[7,8]}$.

O objetivo deste trabalho foi avaliar os danos celulares não específicos (citotoxicicidade) de três polímeros epoxídicos usando a resina líquida do tipo éter diglicidílico do bisfenol-A (DGEBA) com três agentes de cura do tipo poliamina alifática de maneira independente: trietilenotetramina (TETA), 1-(2-aminoetil)piperazina (AEP) e 5-amino1,3,3-trimetilciclohexanometilamina (nomeada, isoforonodiamina (IPD). Para isto foram utilizadas culturas de células de mamíferos (ovários de hamster chinês - CHO), e três ensaios biológicos in vitro de compatibilidade com sangue. O trabalho visa o desenvolvimento de novos materiais à base destes sistemas epoxídicos para serem utilizados como adesivos em artroplastia total de quadril e na preparação de próteses na área odontológica.

\section{Experimental}

\section{Materiais}

As formulações utilizadas estão baseadas no oligômero, produto da reação de epicloridrina e Bisfenol-A, (DGEBA) produto técnico DER 331, produzido e comercializado pela Dow Química do Brasil S.A., com três endurecedores do tipo amina alifática como co-monômeros. Os co-monômeros utilizados foram trietilenotetramina (TETA) produto técnico DEH 24, produzido e comercializado pela da Dow Química do Brasil S.A., 1-(2-aminoetil)piperazina (AEP) e isoforonodiamina produtos P.A. $99 \%$ de pureza, comercializados pela Sigma-Aldrich S.A. do Brasil. A Figura 1 apresenta a estrutura básica e algumas propriedades dos monômeros utilizados. A resina foi desidratada cuidadosamente por tratamento a vácuo a $80^{\circ} \mathrm{C}$ até o desaparecimento das bolhas. Os agentes de cura foram utilizados como recebidos.

\section{Preparação dos polímeros epoxídicos}

Os polímeros foram preparados utilizando proporções estequiométricas (equivalentes de grupos epoxídicos/equivalentes de hidrogênios amina, e/a = 1). Isto foi baseado na determinação destes grupos funcionais por métodos de titulação química $^{[9,10]}$. Todas as formulações preparadas foram agitadas à temperatura ambiente $\left(25^{\circ} \mathrm{C}\right)$ por 1 minutos para assegurar a dissolução do endurecedor e depois foram vazadas em moldes de silicone de $14 \mathrm{~mm} \times 14 \mathrm{~mm} \times 4 \mathrm{~mm}$. O programa de cura usado foi de duas etapas. A primeira etapa, 24 horas à temperatura ambiente, e a segunda, em condições isotérmicas que permitem alcançar a conversão máxima, o que foi otimizado por estudos calorimétricos anteriores (DSC) ${ }^{[11,12]}$. Os materiais após o programa de cura foram resfriados lentamente até chegar à temperatura ambiente. Então foram retirados do molde e maquinados a seco até alcançar a forma de placas com caras paralelas $(12 \mathrm{~mm} \times 12 \mathrm{~mm} \times 2 \mathrm{~mm}$ ). Para os ensaios biológicos a superfície de uma das caras da placa de $12 \mathrm{~mm}$ foi lixada com papel 220, 340, 400 e 600, polida cuidadosamente, lavada com solução salina $(0,1 \mathrm{M}, \mathrm{NaCl})$ e esterilizada por radiação de raios gama, dose de $25 \mathrm{kGy}$.

\section{Ensaios biológicos}

Ensaios in vitro de compatibilidade entre os polímeros e o sangue foram estudados usando quatro bioensaios: adsorção protéica, adesão plaquetária, formação de trombos e citotoxicidade. Estes ensaios são sensíveis, reproduzíveis e quantificáveis o que pode ser utilizado para verificar a compatibilidade com o sangue dos materiais preparados. Estes tipos de ensaios apresentam como vantagem que são obtidas informações do comportamento biológico em relativamente curto período de tempo sem sacrifício de animais de experimentação.

Os ensaios de adsorção protéica, adesão plaquetária e formação de trombos foram realizados de acordo com a metodologia divulgada em trabalhos anteriores ${ }^{[13,14]}$. O ensaio de citotoxicidade foi realizado de acordo com a norma ISO $10993^{[15]}$.

\section{Adsorção protéica}

Neste trabalho foram selecionadas duas proteínas, albumina humana (HSA) e fibrinogênio humano (HFb). A albumina humana resulta uma proteína predominante no sangue, excedendo em abundancia com o resto das proteínas do plasma $^{[16]}$. Soluções de $10 \mu \mathrm{g} \cdot \mathrm{mL}^{-1}$ de HSA (Aldrich 99\% de pureza) e $1 \mathrm{mg} \cdot \mathrm{mL}^{-1}$ de $\mathrm{HFb}$ (Aldrich $99 \%$ de pureza) foram preparadas separadamente em solução aquosa a pH 7,2 e força iônica de 0,01 M (PBS). As amostras de polímeros foram colocadas em tubos de Teflon ${ }^{\circledR}$ com um volume de solução (PBS) de $6 \mathrm{~mL}$ durante 2 horas a $37^{\circ} \mathrm{C}$. A quantidade de proteína adsorvida foi determinada espectroscopicamente usando um espectrofotômetro UV/VIS (Cary 50, Varian) pela diferença entre a concentração de HSA e HFb antes e depois do contato com os polímeros. A concentração protéica foi avaliada de acordo com o método de Bradford ${ }^{[17]}$. 


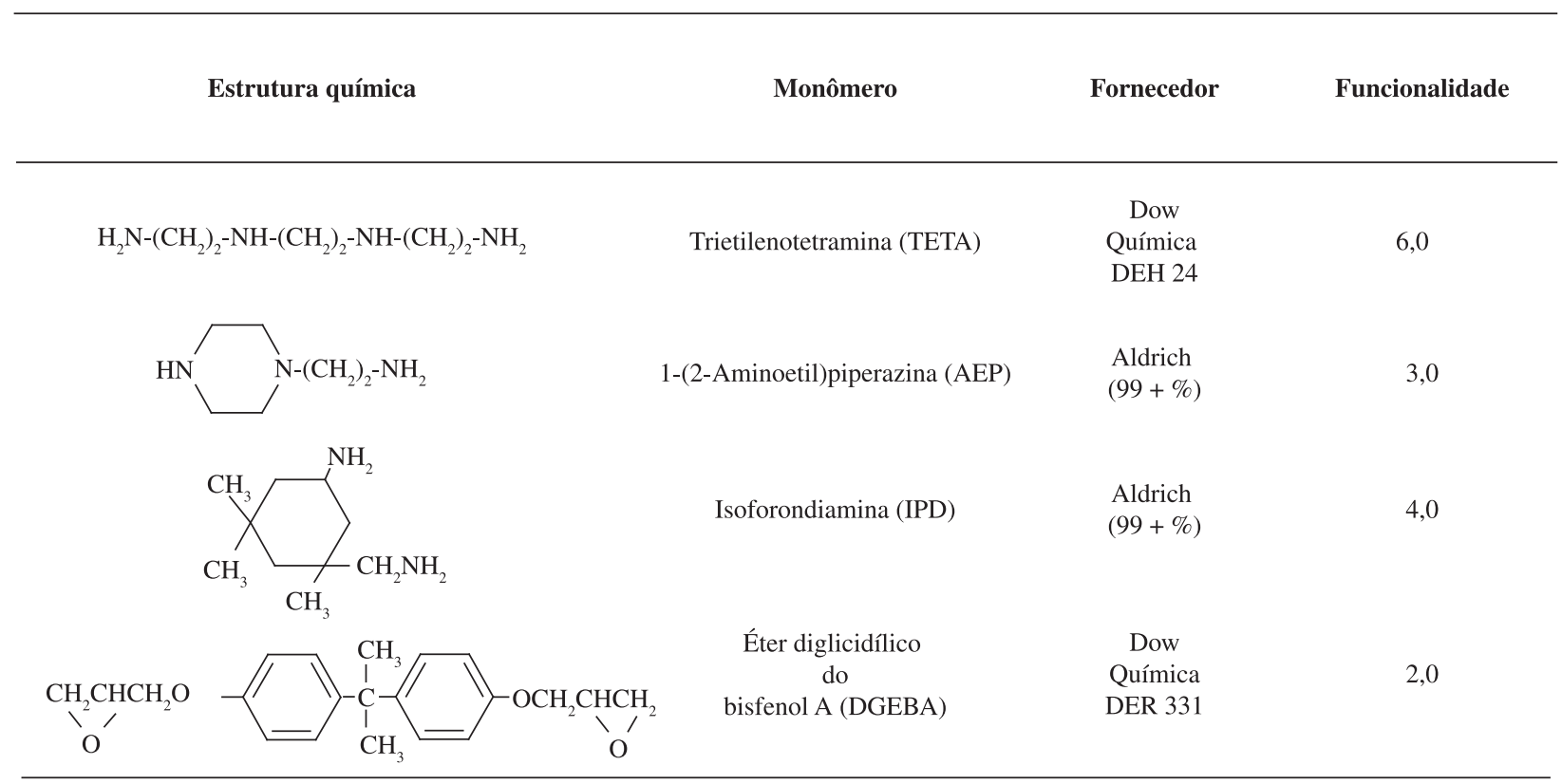

Figura 1. Estrutura básica e algumas propriedades dos monômeros utilizados.

O método de Bradford é uma técnica para a determinação de proteínas totais que utiliza o corante de "Coomassie brilliant blue" BG-250. Este método é baseado na interação entre o corante BG-250 e macromoléculas de proteínas que contém aminoácidos de cadeias laterais básicas ou aromáticas. A interação entre a proteína de alto peso molecular e o corante BG-250 provoca o deslocamento do equilíbrio do corante para a forma aniônica, que absorve fortemente em $595 \mathrm{~nm}$.

\section{Adesão plaquetária}

$\mathrm{Na}$ superfície de cada polímero foram depositados $2 \mathrm{~mL}$ de sangue humano recentemente coletado em sistema para coleta a vácuo (Vacuette ${ }^{\circledR}$ ). Depois de um tempo de contato de 180 segundos, a superfície foi lavada cuidadosamente com solução salina $(0,1 \mathrm{M}, \mathrm{NaCl})$, até remover todo o componente sanguíneo que não foi aderido na superfície. $\mathrm{O}$ valor médio da concentração de plaquetas aderidas foi obtido a partir de cinco micrografías (SEM, Phillips XL 30) considerando uma superfície de $1 \mathrm{~cm}^{2}$ para cada material. A análise quantitativa do processo de adesão de plaquetas sanguíneas nas superfícies sintéticas foi validada através da contagem eletrônica das plaquetas no sangue inicialmente coletado e após seu contato com as superfícies sintéticas. O equipamento utilizado no processo de validação foi o sistema para análise hematológica Advia ${ }^{\circledR} 120$ (Bayer).

\section{Formação de trombos}

O sangue humano foi adicionado a uma parte de ácidocitrato-dextrosa $(\mathrm{ACD})$ para nove partes de sangue. $\mathrm{O}$ resultante ACD - sangue foi colocado numa lamina de vidro e na superfície da placa do material polimérico tratado. A coagulação foi iniciada por adição de solução aquosa de $\mathrm{CaCl}_{2}$, e o trombo formado foi monitorado por pesagem durante 40 minutos. Os pesos relativos de trombos formados nas diferentes amostras foram determinados tendo como referência o $100 \%$ de trombos formados na placa de vidro.

\section{Teste de citotoxicidade em cultura celular}

A citotoxicidade das amostras foi avaliada usando células de ovário de hamster chinês (CHO), ATCC CHO k1 (Tipo American Culture Collection, ATCC), de acordo com a norma ISO ${ }^{[15]}$.

Um monocultivo de $\mathrm{CHO}$ foi preparado, e devidamente tratado e a partir deste uma suspensão celular foi obtida. A suspensão celular fresca é colocada em contato com a superfície das amostras tratadas em placas petri $\left(15 \times 60 \mathrm{~mm}^{2}\right)$ usando diferentes concentrações de suspensão e controles positivos e negativos de solução 0,02 vol. \% de fenol e polietileno de ultra-alta massa molecular (UHMWPE), respectivamente. Cada concentração de suspensão celular foi ensaiada por triplicata para cada material. O potencial de toxicidade foi expresso por um índice de citotoxicidade, IC50 (\%) que representa a concentração que suprime a formação de colônias de células por 50\% em comparação com o controle.

\section{Resultados e Discussão}

\section{Adsorção proteica}

A importância atribuída à interação entre as proteínas e a superfícies dos materiais é geralmente considerada como um passo fundamental para o comportamento bem sucedido de qualquer biomaterial. Após o contacto com fluidos fisiológicos, muitas proteínas adsorvidas nas superfícies induzem interações indiretas das células com o material ${ }^{[18]}$. A adsorção 


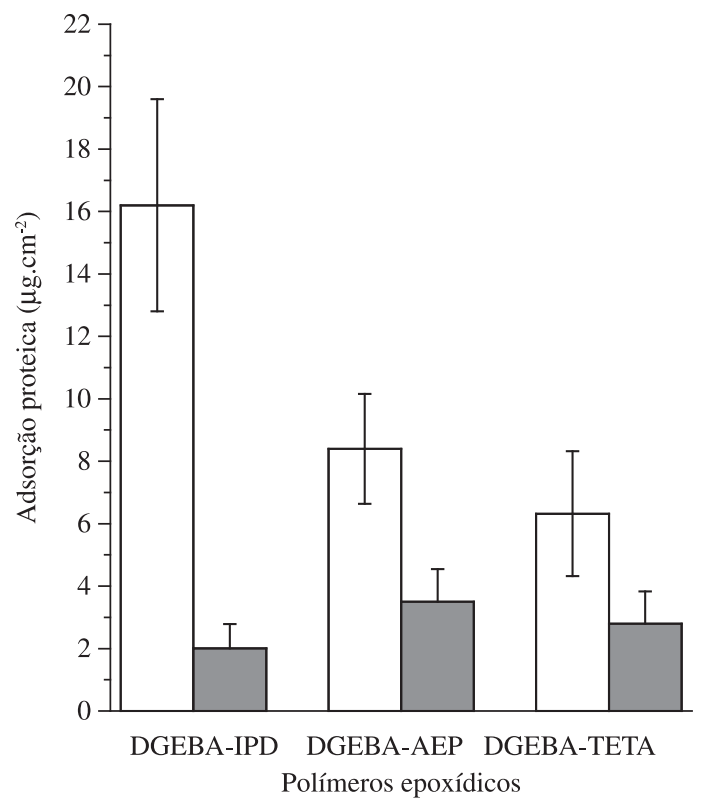

Figura 2. Adsorção de proteínas séricas sobre a superfície dos polímeros epoxídicos. Em branco e preto estão representados a adsorção de HSA e HFB, respectivamente.

superficial de albumina humana (HSA) e fibrinogênio (HFB) nos materiais preparados foram estudados com o objetivo de obter informação da extensão da interação superficial das proteínas com os polímeros no fluido fisiológico.

Para os materiais epoxídicos estudados verificou-se a ocorrência de uma maior adsorção de albumina humana, HSA, quando comparada à adsorção de fibrinogênio (HFB) (Figura 2). Está bem estabelecido na literatura que o tipo e quantidade de proteínas sanguíneas adsorvidas na superfície biomaterial/sangue em grande parte induz a ativação plaquetária superficial ${ }^{[19]}$. Neste sentido, a adsorção de fibrinogênio é conhecida que acelera e ativa a adesão plaquetária. Entretanto, a adsorção de albumina na superfície dos materiais pode inibir a ativação plaquetária e, consequentemente, não promove a formação de coágulos ${ }^{[20]}$. Assim, a maior adsorção superficial de HSA quando comparada à adsorção de $\mathrm{HFb}$ pode ser um bom indicativo de uma baixa ativação e adesão de plaquetas pela superfície destes materiais. Por tanto, a maior adsorção de albumina humana (HSA) nos materiais (Figura 2) sugere que a superfície dos polímeros apresenta um comportamento não trombogênico.

\section{Ativação e adesão plaquetárea}

As micrografias eletrônicas (SEM) das superfícies dos polímeros epoxídicos, após o contato com o sangue são mostradas na Figura 3. Na figura observa-se que a superfície do polímero que utiliza como co-monômero TETA apresentou uma atividade trombogênica mais significava (Figura 3a), quando comparada à superfície dos outros dois polímeros (Figura 3b, c).

A exposição da superfície do polímero que utiliza TETA ao sangue resultou em uma grande ativação e adesão plaque-

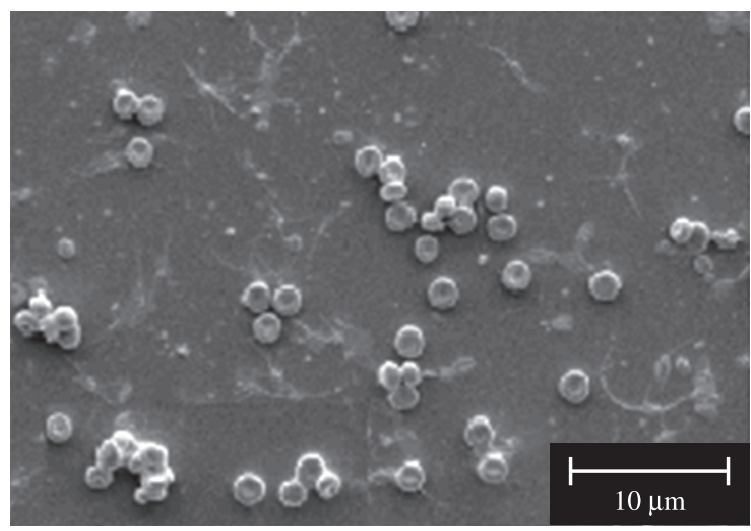

(a)

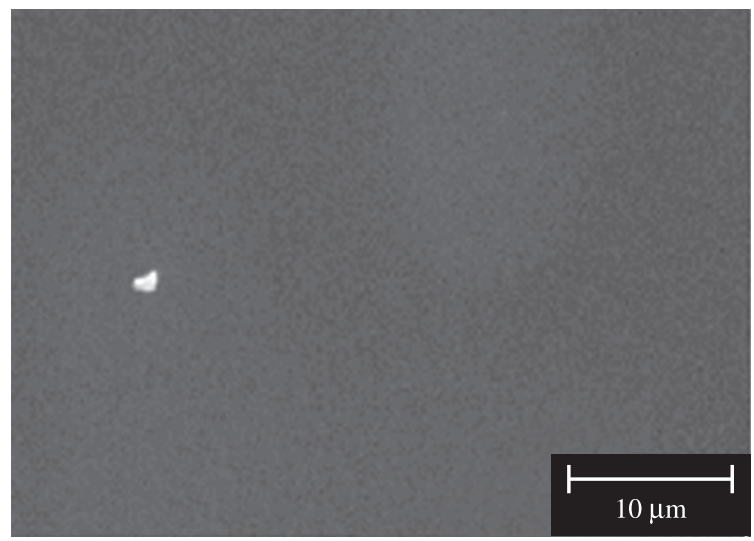

(b)

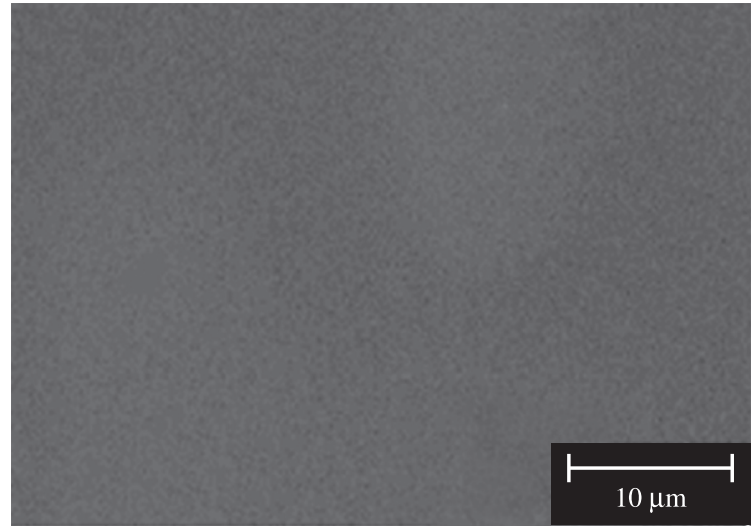

(c)

Figura 3. a) Micrografias eletrônicas (SEM) da superfície dos polímeros DGEBA-TETA; b) DGEBA-AEP; e c) DGEBA-IPD, após incubação em sangue humano a $37^{\circ} \mathrm{C}$ durante 180 segundos.

tária formando pequenas áreas de agregados plaquetários e fibras (fibrina). Isto ocorre devido à polimerização da fibrina de fibrinogênio na superfície do polímero. Por outro lado, a ativação e adesão de plaquetas não foram observadas na superfície dos polímeros formulados com poliaminas cicloalifáticas (AEP e IPD). A superfície destes polímeros resultou sem plaquetas e sem a formação de trombos.

Este resultado mostra que a afinidade pela albumina (HSA) da superfície do polímero formulado com TETA não foi suficiente para inibir a adesão de plaquetas. Essa ativação 


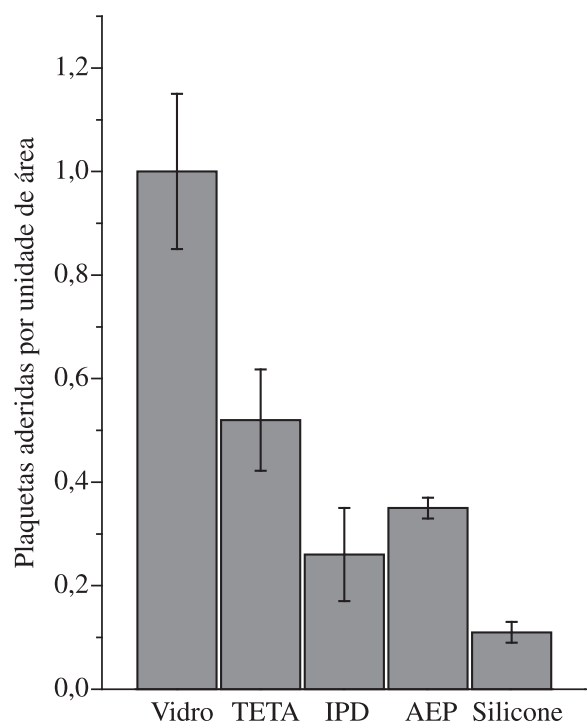

Figura 4. Relação de plaquetas aderidas por unidade de área $\left(100.000 \mu . \mathrm{m}^{2}\right)$ nas superfícies dos polímeros após exposição ao sangue humano. Vidro e silicone de uso medicinal foram usados como controle positivo e negativo, respectivamente.

e adesão de plaquetas está relacionada à primeira etapa do processo de formação de trombos ${ }^{[20]}$.

A relação de plaquetas aderidas por unidade de área após a incubação em sangue humana a $37^{\circ} \mathrm{C}$ durante 180 segundos é mostrado na Figura 4. A proporção de plaquetas aderidas na superfície por unidade de área para o polímero que utiliza TETA foi significativamente mais alta do que para os polímeros que utilizaram AEP, IPD e o silicone grau médico (usado como controle de negativo). Isto pode ser atribuído à alta adsorção de albumina humana (HSA) pela superfície destes dois polímeros.

\section{Cinética da formação de trombos}

As cinéticas da formação de trombos depois de exposição da superfície dos polímeros com sangue humano são mostradas na Figura 5. A formação de trombos diminuiu drasticamente na superfície dos polímeros formulados com poliaminas cicloalifáticas (AEP e IPD) quando comparada ao polímero formulado com o co-monômero TETA. Este resultado era esperado e está de acordo com os resultados de adsorção superficial da albumina humana (HSA) por estes polímeros. Por tanto, a mais baixa adsorção de fibrinogênio $(\mathrm{HFb})$ parece inibir a ativação da coagulação nas formulações com AEP e IPD. Por outro lado, é possível dizer que o polímero que utiliza TETA não pode ser utilizado para aplicações cardiovasculares sem a realização de alguma modificação superficial devido à alta formação de trombos.

\section{Citotoxicidade}

Está bem estabelecido na literatura que a biocompatibilidade é certamente controlada pela atividade celular na interface do material sintético ${ }^{[22]}$. O ensaio de citotoxicidade representa a fase inicial do ensaio de biocompatibilidade de um material com potencialidades para aplicações médicas, sendo

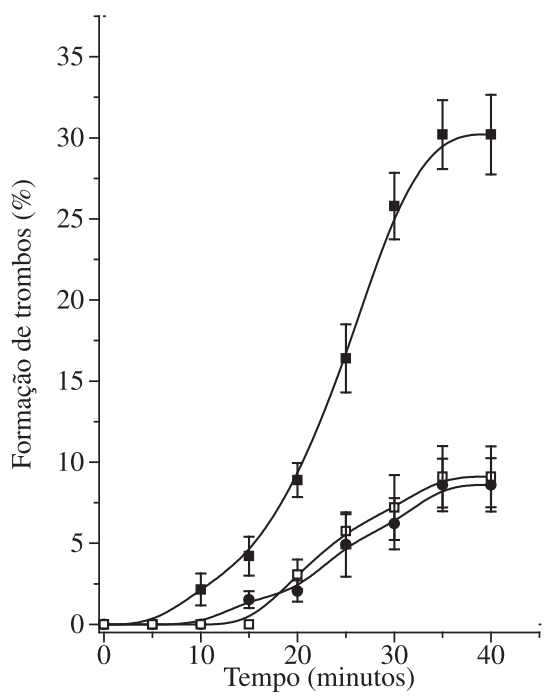

Figura 5. Cinética de formação de trombos na superfície dos polímeros for-

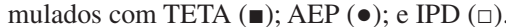

utilizado em uma primeira análise para avaliar se o material apresenta características biocompatíveis, para depois avaliar sua interação com o tecido biológico. Este ensaio é importante para a realização de estudos in vivo, com a finalidade de avaliarmos o comportamento do material dentro do meio biológico e confirmar que o material pode ser utilizado como biomaterial.

O nível de citotoxicidade dos polímeros epoxídicos encontrado foi relativamente baixo, conforme pode ser observado na Figura 6. O material utilizado como controle positivo, (solução de fenol), apresentou atividade citotóxica extremamente alta, pois praticamente não restaram colônias sobreviventes sobre a placa de controle. Para os três polímeros, o percentual de colô-

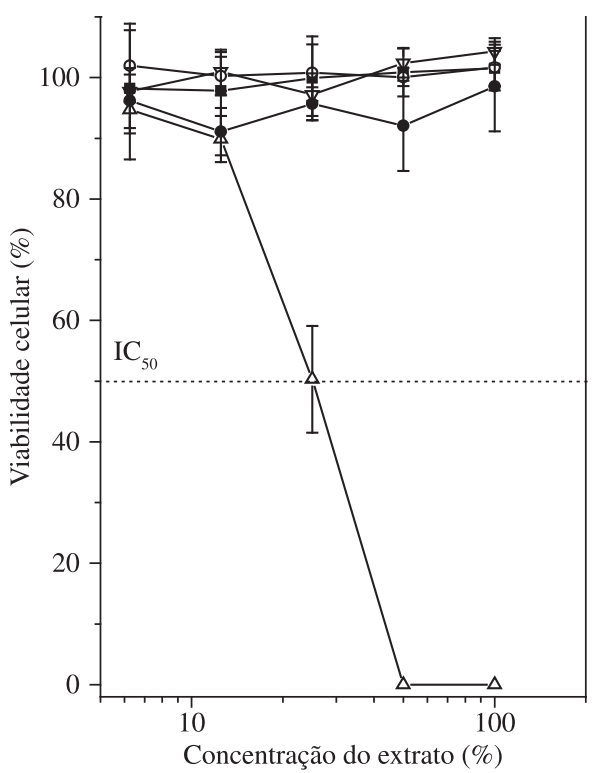

Figura 6. Citoxicidade dos extratos dos polímeros formulados com os co-

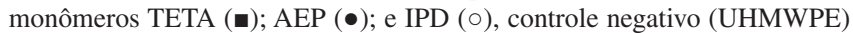
$(\nabla)$, e controle positivo (fenol) $(\triangle)$, em contato com células de ovário de hamster chinês. 
nias sobreviventes é bem elevado, indicando que eles apresentam uma baixa toxicidade às células de ovário de hamster chinês.

Baseado nos resultados obtidos neste trabalho e visando algumas potencialidades dos polímeros epoxídicos usando o oligômero do tipo éter de diglicidílico do bisphenol-A com poliaminas alifáticas para aplicações medicas estudos in vivo utilizando animais de laboratório, estão sendo realizados em nosso laboratório. A preparação de dispositivos protéticos para a área odontológica e a realização de ensaios de adesão de ligas de titânio com tecido ósseo estão também sendo realizados em nosso laboratório e os resultados serão posteriormente publicados.

\section{Conclusões}

As propriedades biológicas dos três materiais epoxídicos usando o oligômero do tipo éter diglicidílico do bisfenol-A com os três co-monômeros do tipo amina alifática de maneira independente tais como trietilenotetramina, 1-(2-aminoetil) piperazina (AEP) e isophorondiamina (IPD) foram avaliadas usando quatro ensaios biológicos in vitro. A alta adsorção de albumina e baixa adsorção de fibrinogênio, assim como também a supressão de ativação de plaquetas e a boa citocompatibilidade dos polímeros formulados com poliaminas cicloalifáticas (AEP e IPD), indicou que estes materiais apresentam boas características para aplicações medicas. Dos polímeros avaliados o polímero formulado com TETA apresentou a maior formação de trombos o que sugere que este material não pode ser utilizado para aplicações cardiovasculares sem a realização de alguma modificação superficial. Os resultados de citotoxicidade indicam que todos os polímeros estudados são biocompatíveis com as células de ovário de hamster chinês. Observa-se que os resultados obtidos neste trabalho demonstram a possibilidade de obtenção de novos tipos de revestimentos não trombogênicos a partir de polímeros epoxídicos, sobretudo àqueles baseados na isoforonodiamina (IPD). Os sitemas epoxídicos baseados nas aminas AEP e TETA não preenchem um dos prérequisitos da biocompatibilidade, mas parecem ser adequados para utilização no projeto de revestimentos que não envolvam o contato direto com o sangue, uma vez que não apresentam citotoxicidade. A utilização dos estudos desenvolvidos neste trabalho poderá ser estendida para o desenvolvimento de revestimentos não trombogênicos a exemplo das resinas epoxídicas baseadas no IPD ou não citotóxicos (TETA, AEP).

\section{Agradecimentos}

Os autores agradecem o apoio financeiro dos órgãos de fomento brasileiras CNPq e FAPEMIG (ref. TEC 00242/07) que tornou possível a realização deste trabalho.

\section{Referências Bibliográficas}

1. Boesel, L. F. \& Reis, R. L. - Science, 33, p.180 (2008).
2. Rusen, E.; Zaharia, C.; Zecherua, T.; Marculescu, B.; Filmon, R.; Chappard, D.; Badulescu, R. \& Cincua, C. J. Biom., 40, (15), p.3349 (2007).

3. Suqing, S. \& Jun, N. - Dent. Mat., 24, p.530 (2008).

4. Jirun, S. \& Sheng, L. G. - Dent. Mat., 24, p.228 (2008).

5. Millich, F.; Jeang, L.; Eick, J. D.; Chappelow, C. C. \& Pinzino, C. S. - Journal of Dental Research. 77, p.603 (1998).

6. Tilbrook, D. A. - Biomaterials, 21, p.1743 (2000).

7. Abraham, G. A.; De Queiroz, A. A. A. \& Roman, S. J. Biomaterials, 23, p.1625 (2002).

8. De Queiroz, A. A. A.; Barrak, E. R. A.; Gil, H. A. C. \& Higa, O. Z. - J. Biomat. Sci. Polym. Ed., 8, p.667 (1997).

9. González Garcia F.; Da Silva, P. M.; Soares, B. G. \& Rieumont, J. - Polym. Test., 26, p.95 (2007).

10. American Society for Testing and Materials. "Standard test methods for epoxy content of epoxy resins - ASTM D 1652 - 97’, West Conshohocken (1997).

11. González Garcia, F.; Soares, B. G.; Pita, V. J. R. R.; Sánchez, R. \& Rieumont, J. - J. Appl. Polym. Sci., 107, p.2047 (2007).

12. González Garcia, F.; Miguez, E. \& Soares, B. G. - Polímeros: Cienc Tecnol., 15, p.261 (2005).

13. González Garcia, F.; Leyva, M. E.; De Queiroz, A. A. A. \& Higa, O. Z. - J. Appl. Polym. Sci., 112, p.1215 (2009).

14. De Queiroz, A. A. A.; Gallardo, A.; Román \& S. J.; Higa, O. Z. - J. Biomat. Sci.: Polymer Edition, 7, p.523 (1995).

15. International Standard Organization. "Biological evaluation of medical devices tests for citotoxicity: in vitro methods", ISO 10993-5 (1999).

16. Goodman, S. L.; Cooper, S. L. \& Albrecht, R. M. - J. Biomat. Sci.: Polymer Edition, 2, p.147 (1991).

17. Bradford, M. M. - Analytical Biochem., 72, p.248 (1976).

18. Dolatshahi-Pirouz, A.; Rechendorff, K.; Hovgaard, M. B.; Foss, M.; Chevallier, J. \& Besenbacher F. - Colloids and Surfaces B: Biointerfaces, 66, p.53 (2008).

19. Leonard, E. F. \& Vroman, L. - J. Biomat. Sci: Polymer Edition, 3, p.95 (1991).

20. Gibbins, J. M. - Platelet adhesion signalling and the regulation of thrombus formation. J. Cell Sci., 117, p.3415 (2004).

21. Rao, G. H. R. \& Chandy, T. - Bull. Mater. Sci., 22, p.633 (1999).

22. Hench, L. L. \& Ethridge, E. C. - (Eds.). "Biomaterials: An Interfacial Approach.” Academic Press, New York (1982).

Enviado: 15/01/09

Reenviado: 11/03/09

Aceito: 23/03/09 